\title{
Renewable Desalination: A Methodology for Cost Comparison
}

EDS Conference, Barcelona, 24.04.2012

Massimo Moser, Franz Trieb, Tobias Fichter, Jürgen Kern*

German Aerospace Center (DLR)

Institute of Technical Thermodynamics

Department of System Analysis and Technology Assessment

*kernenergien - the solar power company 


\section{Water Supply Scenario for MENA}

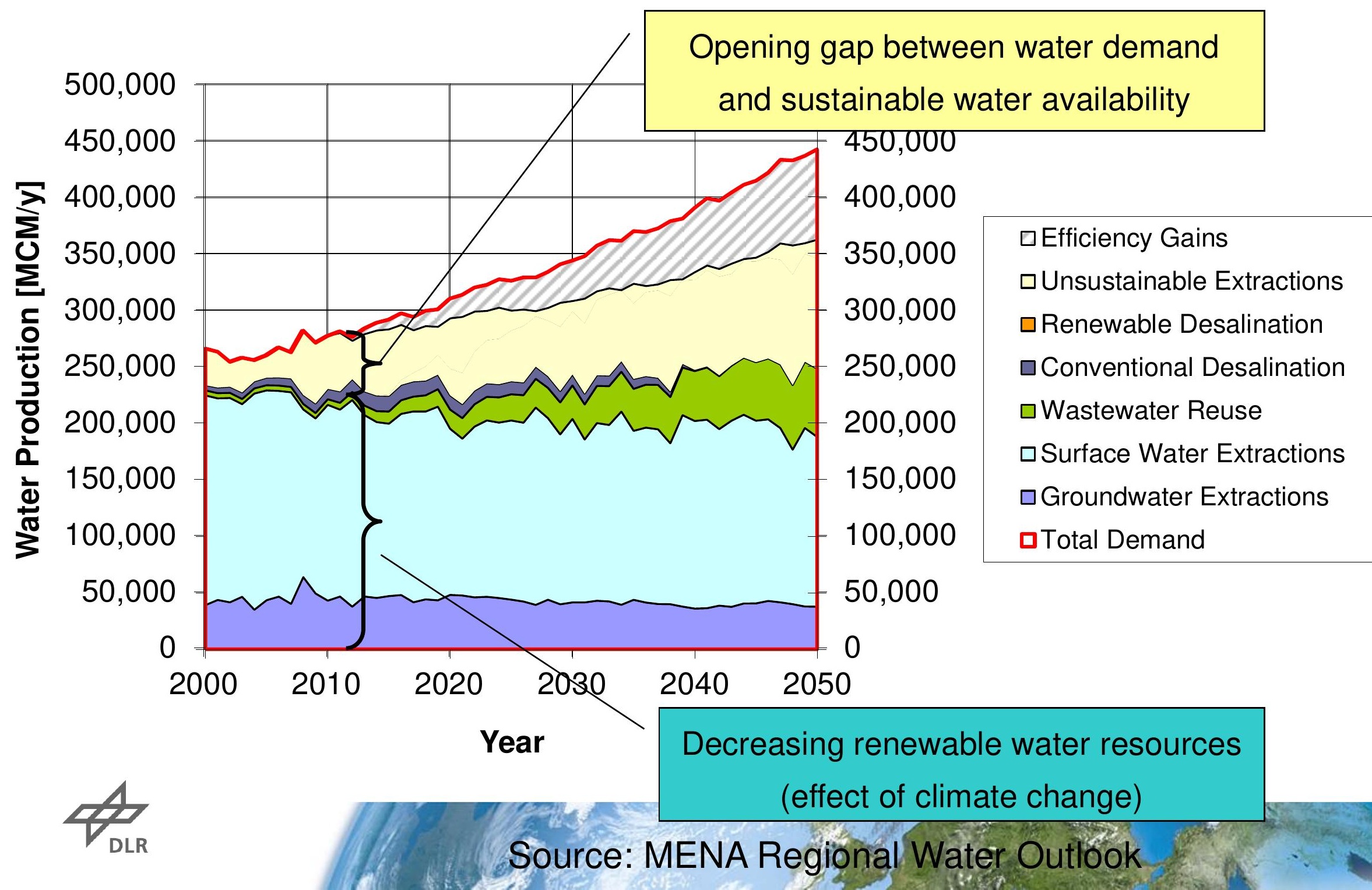




\section{Energy Cost for Conventional Desalination (Example: RO)}

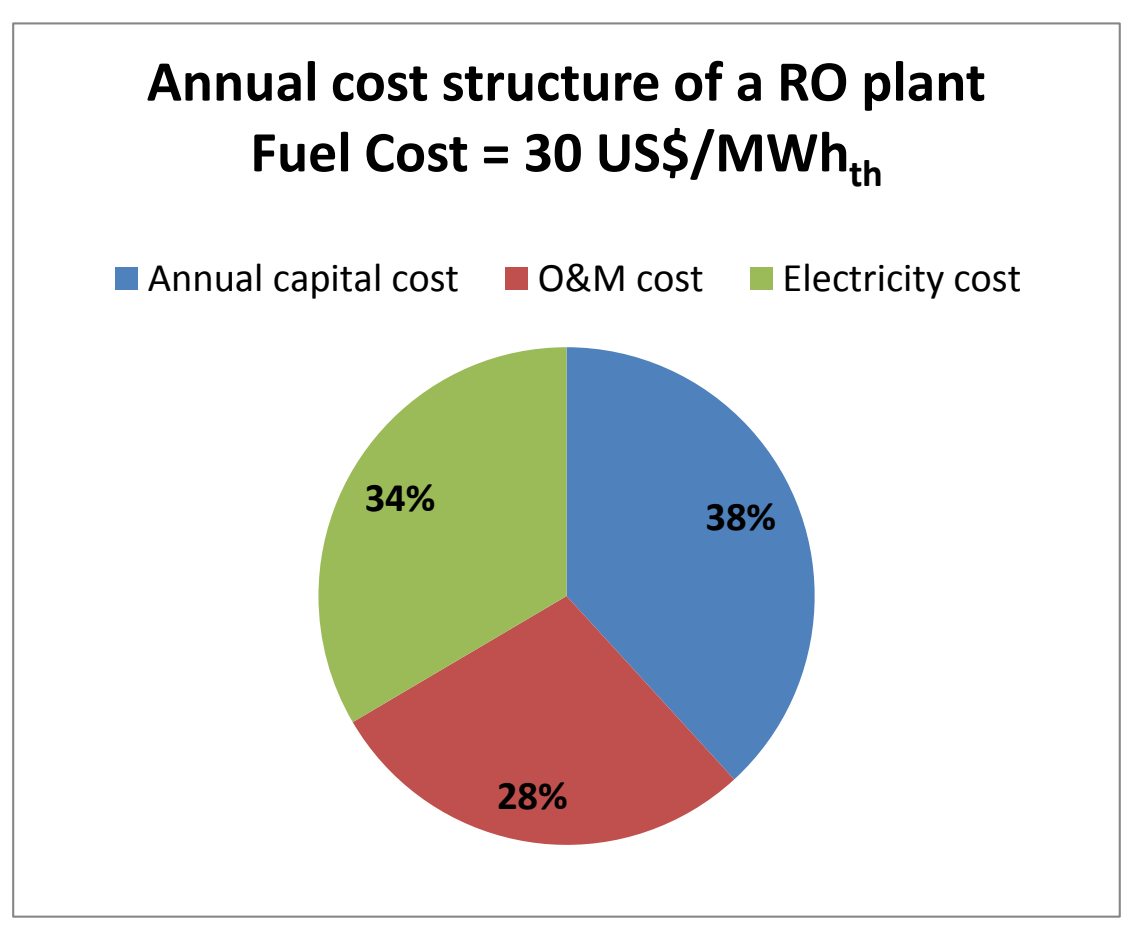

LWC: 1.23 US $\$ / \mathrm{m}^{3}$

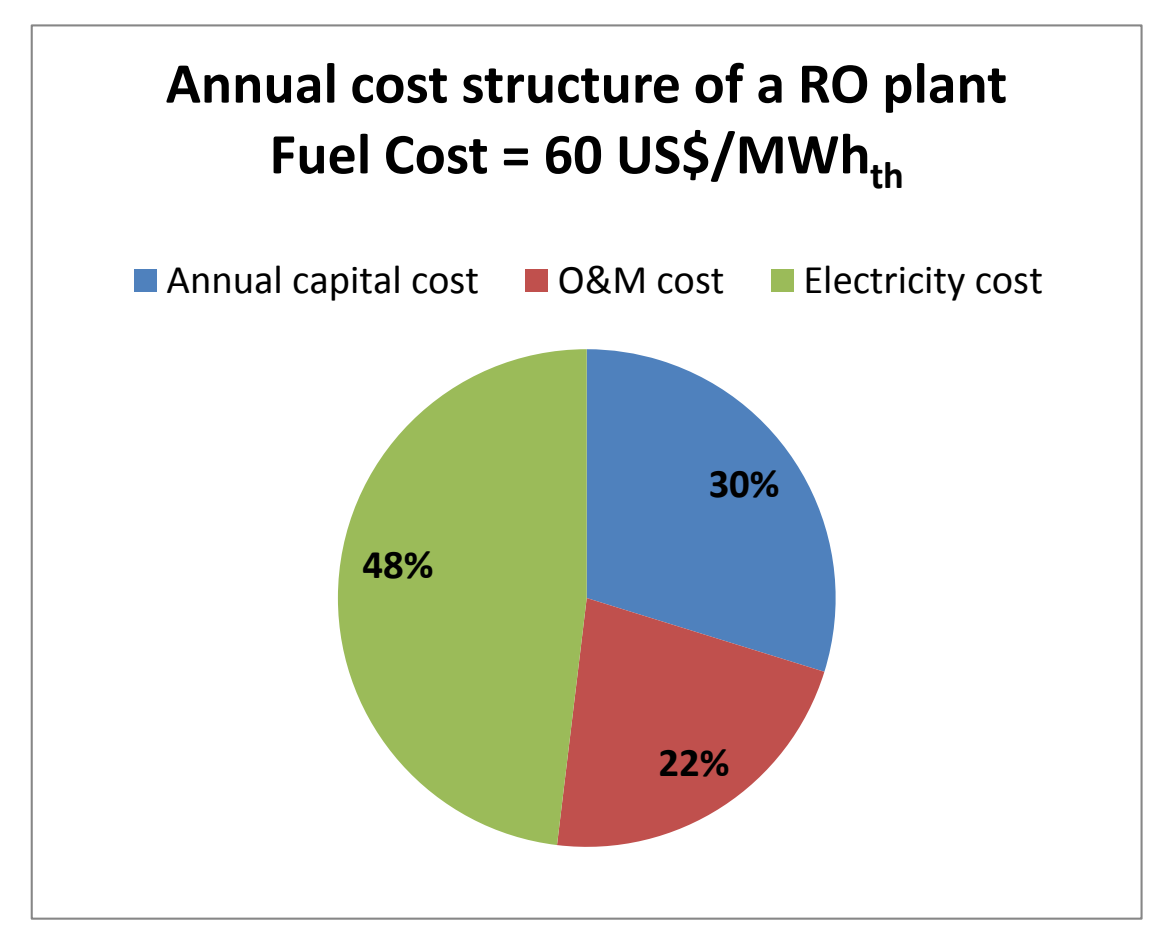

LWC: $1.58 \mathrm{US} \$ / \mathrm{m}^{3}$ 


\section{Fossil fuels cost 2002 - 2012}

- Coal (Australia)

x 4.2

- Crude Oil (Brent) $\times 5.6$

- Natural Gas (Russia) $\times 4.4$
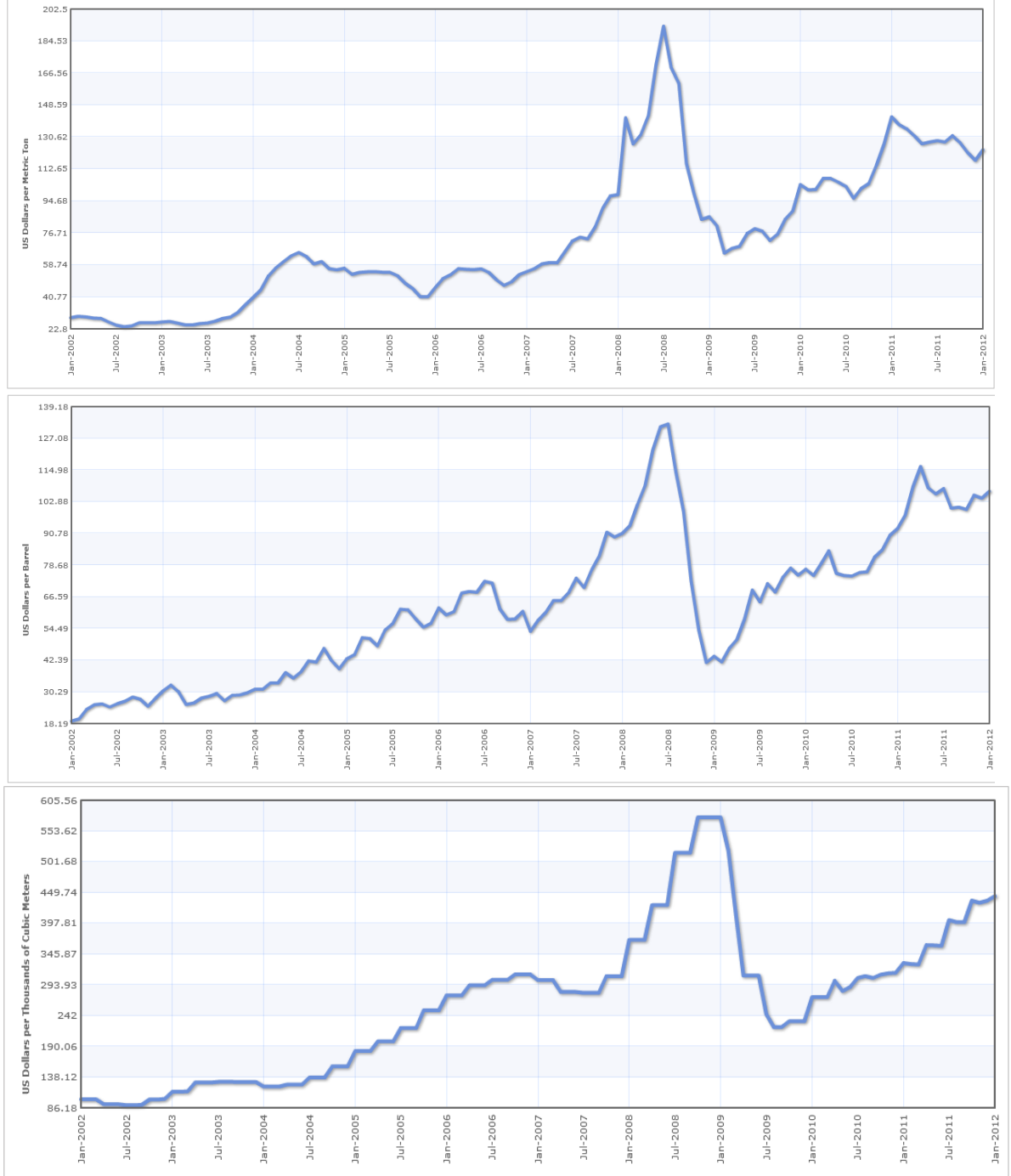


\section{Energy Cost Development of RE-Technologies}

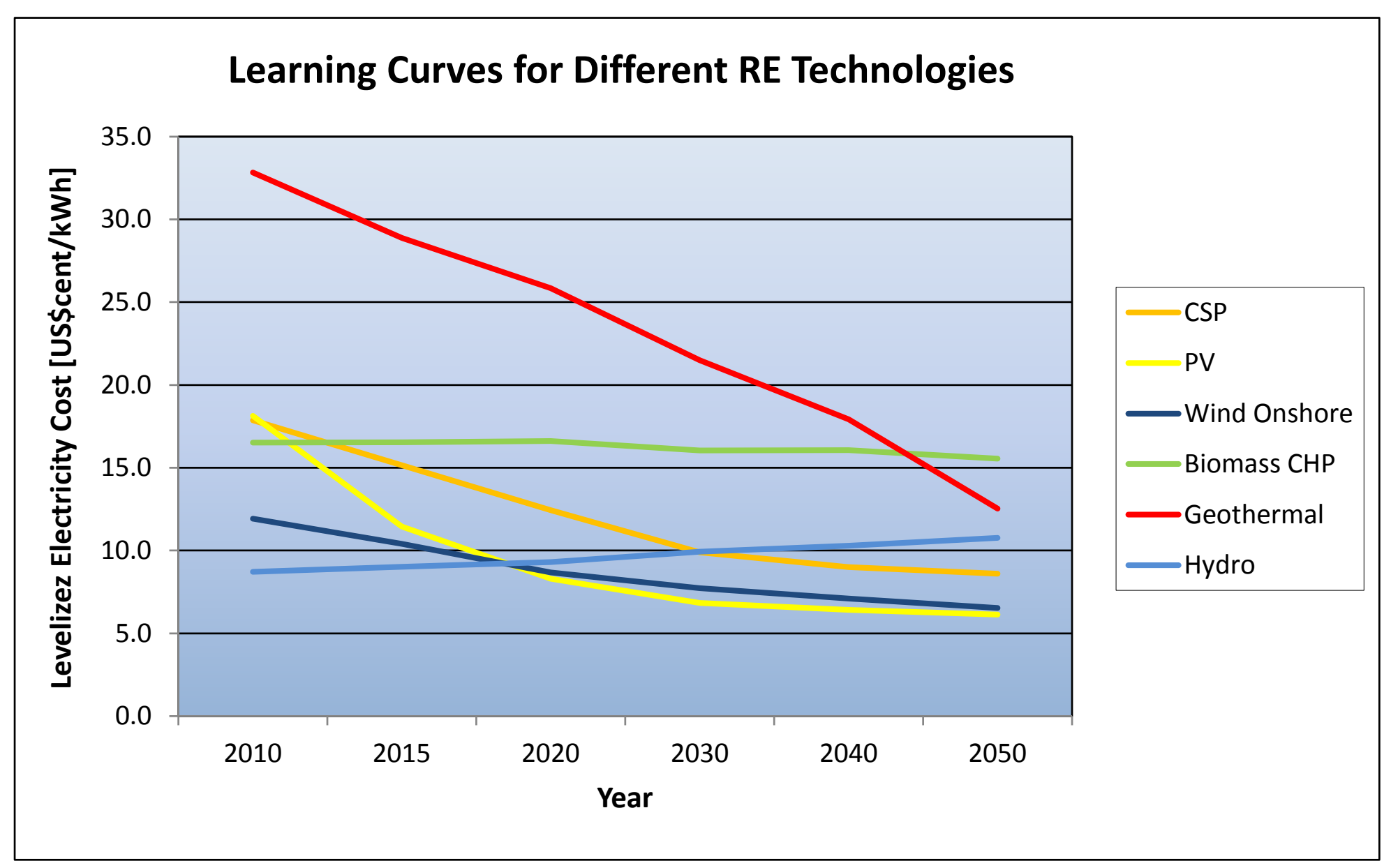

Note: qualitative trends only! 


\section{Typical Electricity Generation Profiles of RE}

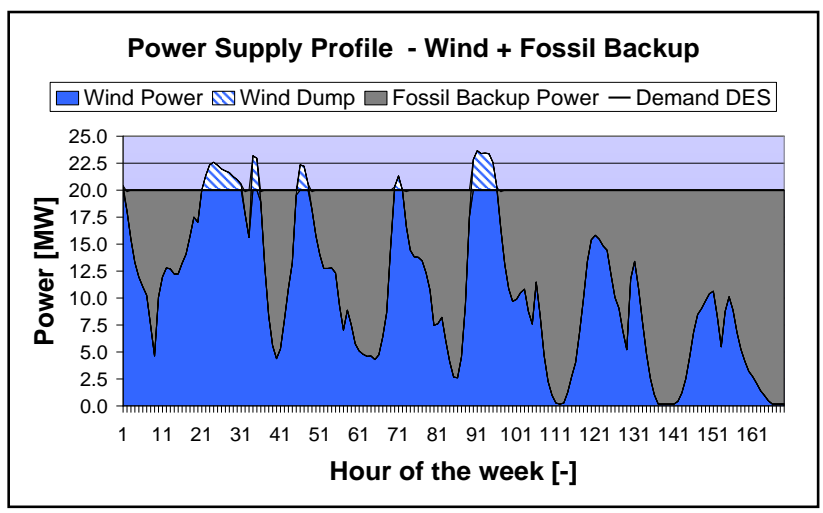

Wind

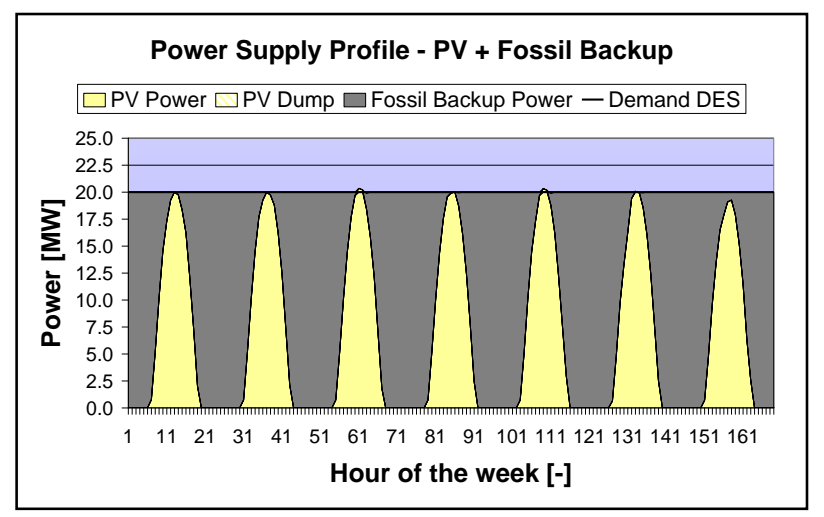

PV

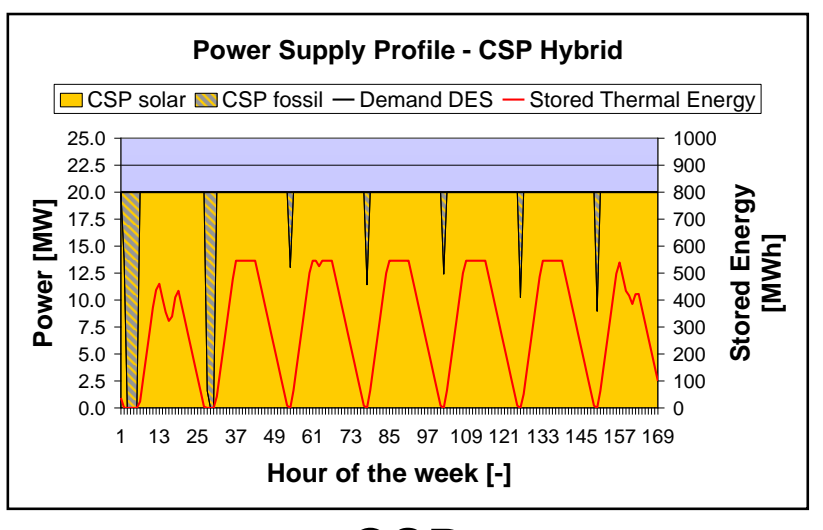

CSP

Large desalination plants require continuous operation

$\rightarrow$ Conflict with the intermittent nature of renewable energies

$\rightarrow$ CSP offers the option of thermal energy storage

$\rightarrow$ Hybrid operation is possible in the same power block (no backup power plant required)

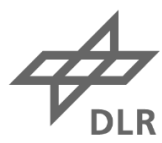




\section{Comparison Methodologies}

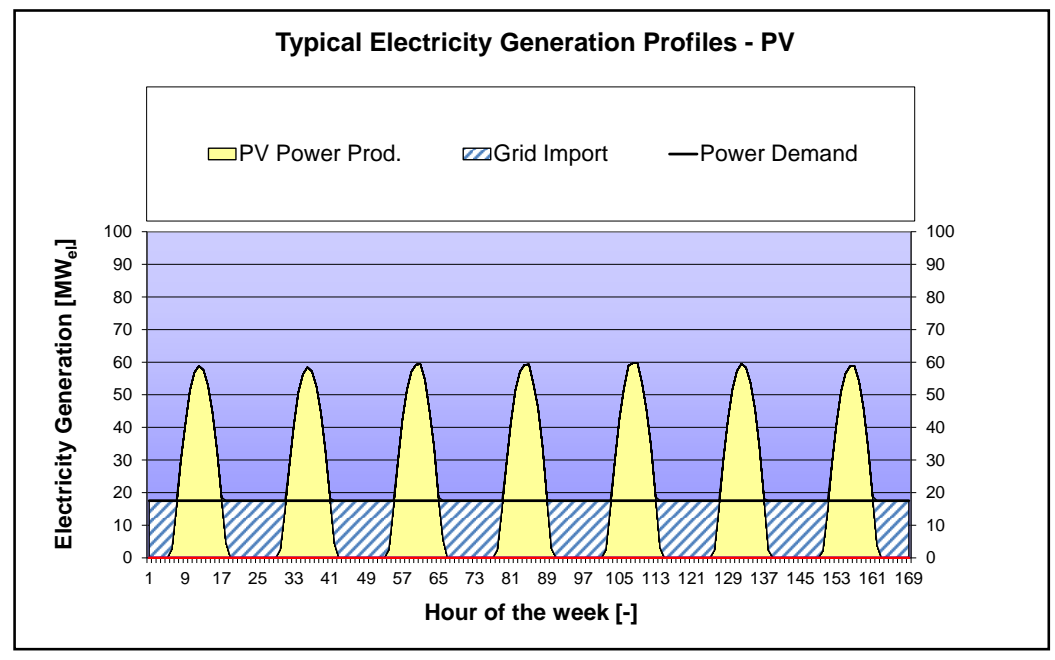

\section{Annual Energy Balance of Load and Supply}

- Options have unequal quality

- Cost externalization

- Fossil backup

- Grid management cost

$\rightarrow$ Cheap, fluctuating RE

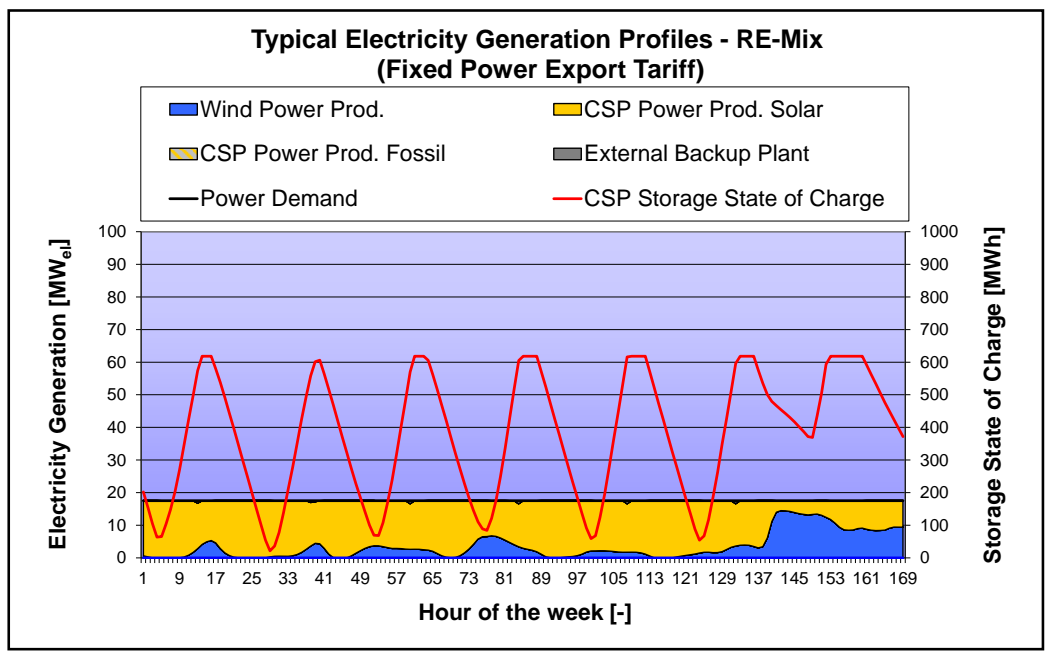

\section{Direct Energy Balance of Load and Supply}

- Options have equal quality

- No cost externalization

$\rightarrow$ RE-Mix including backup and storage 


\section{Energy Cost as Function of RE-Share and Fuel Cost}

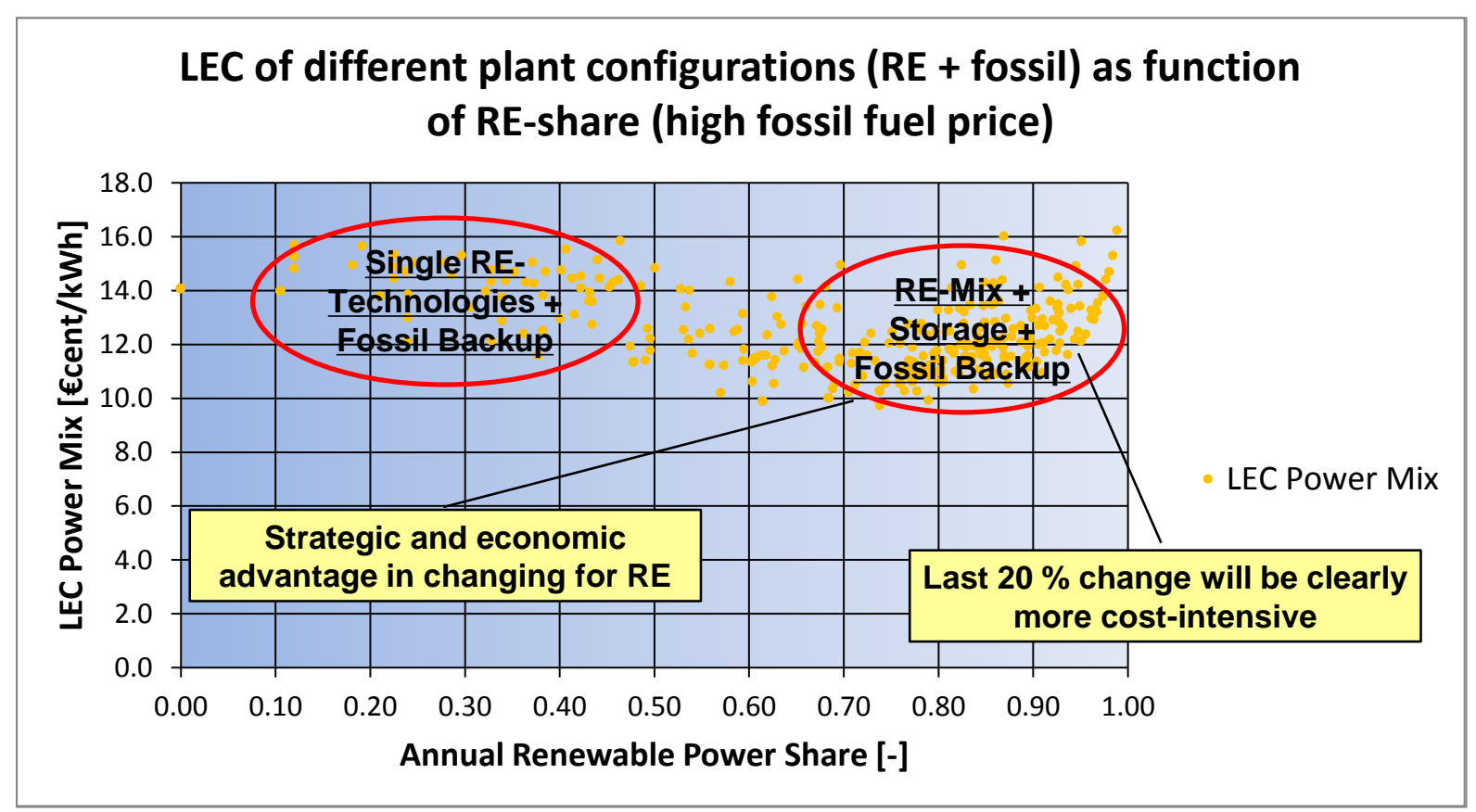

- Direct RO electricity supply (RE and fossil)

- Pre-defined number of configurations (no optimization)

- 2 fossil fuel prices:

- Low: 30 US\$/MWhth

- High: 60 US\$/MWhth 


\section{Effect of different Feed-in Tariff Values for Power Export}

- RO supply / 80 \% EE-Share / Fossil fuel price: 60 US\$/MWhth

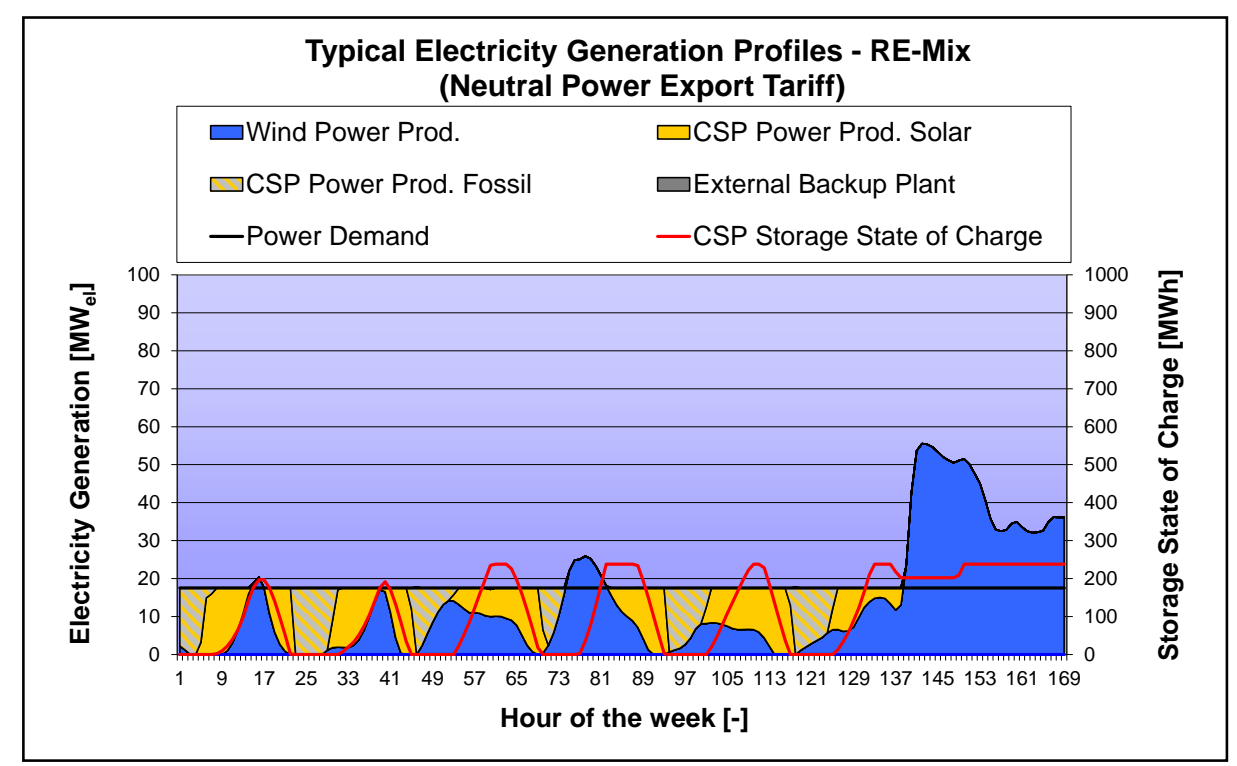

$\underline{\text { Neutral Tariff }}$

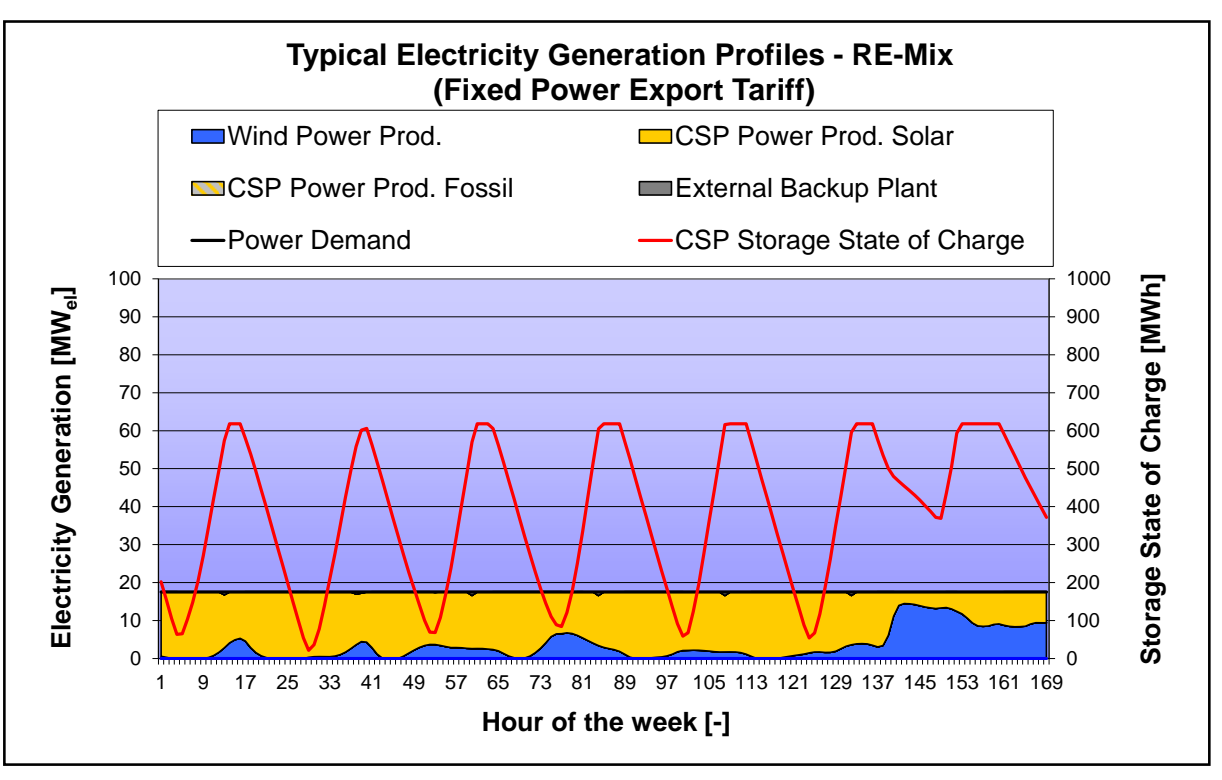

\section{Low Tariff}

$\rightarrow$ High sensitivity of optimal plant configuration on economic boundary conditions! 


\section{Conclusions (1/2)}

- Among other measures, new desalination plants will be required in MENA in order to cover the increasing water demand

- For this purpose, new power plants need to be installed in order to supply firm capacity to the desalination plants

- Fossil fuel prices are prone to high volatility and a clear upward trend

- On the contrary, Renewable Energies (RE) represent a key element for an environmentally friendly, cost stable and low-risk energy supply

- When comparing different supply options, the right question to ask is:

- Which is the most effective technology mix to secure the supply? Rather than

- Which is the cheapest technology? 


\section{Conclusions (2/2)}

- A fair comparison between options should consider configurations which guarantee equal quality of supply (consideration of externalities):

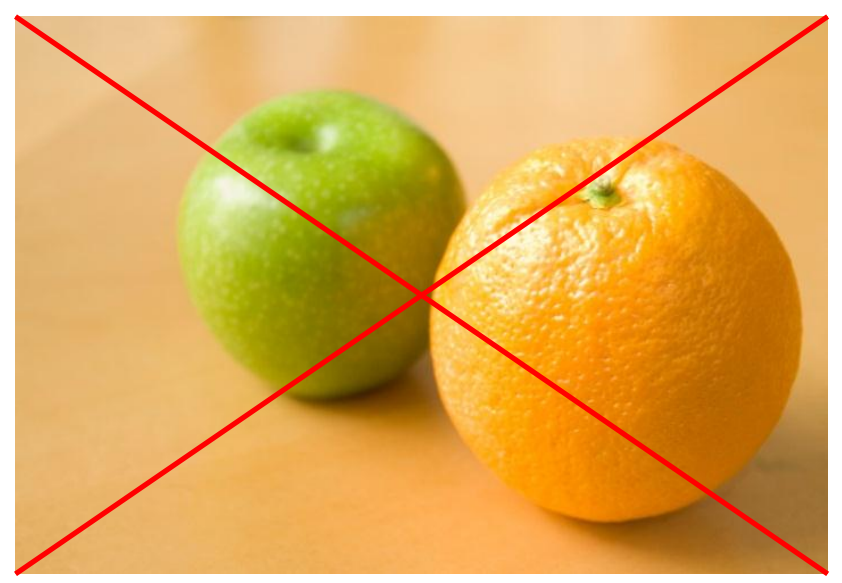

\section{they do not compare!}

- The optimal energy supply for desalination plants will probably consist of a combination of low cost variable power (PV, Wind) and slightly more expensive balancing power (CSP with thermal energy storage) 


\section{Thank you for your attention!}

Contact:

Massimo Moser (massimo.moser@dlr.de) 